\title{
BIOPHYSICS
}

Vol. 5, pp. 1-9 (2009)

doi: $10.2142 /$ biophysics.5.1

\section{The pressure-temperature phase diagram of hen lysozyme at low pH}

\author{
Akihiro Maeno $^{1,2}$, Hiroshi Matsuo ${ }^{3,4}$ and Kazuyuki Akasaka ${ }^{1,2,4}$ \\ ${ }^{1}$ Graduate School of Biology-Oriented Science and Technology, Kinki University, 930 Nishimitani, Kinokawa, Wakayama 649-6493, Japan \\ ${ }^{2}$ RIKEN SPring-8 Center, 1-1-1 Kouto, Sayo, Hyogo 679-5148, Japan \\ ${ }^{3}$ Niigata Industrial Creation Organization, 5-1 Bandaijima, Chuo-ku, Niigata 950-0078, Japan \\ ${ }^{4}$ High Pressure Protein Research Center, Institute of Advanced Technology, Kinki University, 930 Nishimitani, Kinokawa, Wakayama 649- \\ 6493, Japan
}

Received 7 January, 2009; accepted 20 January, 2009

The equilibrium unfolding of hen lysozyme at pH 2 was studied as a function of pressure $(0.1 \sim 700 \mathrm{MPa})$ and temperature $\left(-10^{\circ} \mathrm{C} \sim 50^{\circ} \mathrm{C}\right)$ using $\operatorname{Trp}$ fluorescence as monitor supplemented by variable pressure ${ }^{1} \mathrm{H}$ NMR spectroscopy (0.1 400 MPa). The unfolding profiles monitored by the two methods allowed the two-state equilibrium analysis between the folded (N) and unfolded $(U)$ conformers. The free energy differences $\Delta G\left(=G_{\mathrm{U}}-G_{\mathrm{N}}\right)$ were evaluated from changes in the wavelength of maximum fluorescence intensity $\left(\lambda_{\max }\right)$ as a function of pressure and temperature. The dependence of $\Delta G$ on temperature exhibits concave curvatures against temperature, showing positive heat capacity changes $\left(\Delta C_{p}=C_{p \mathrm{U}}-C_{p \mathrm{~N}}=1.8-1.9 \mathrm{~kJ} \mathrm{~mol}^{-1} \mathrm{deg}^{-1}\right)$ at all pressures studied $(250 \sim 400 \mathrm{MPa})$, while the temperature $T_{\mathrm{s}}$ for maximal $\Delta G$ increased from about $10^{\circ} \mathrm{C}$ at $250 \mathrm{MPa}$ to about $40^{\circ} \mathrm{C}$ at $550 \mathrm{MPa}$. The dependence of $\Delta G$ on pressure gave negative volume changes $\left(\Delta V=V_{\mathrm{U}}-V_{\mathrm{N}}\right)$ upon unfolding at all temperatures studied $\left(-86 \sim-17 \mathrm{ml} \mathrm{mol}^{-1}\right.$ for $-10^{\circ} \mathrm{C} \sim 50^{\circ} \mathrm{C}$ ), which increase significantly with increasing temperature, giving a positive expansivity change $\left(\Delta \alpha \sim 1.07 \mathrm{ml} \mathrm{mol}^{-1} \mathrm{deg}^{-1}\right)$. A phase-diagram between $N$ and $U$ (for $\Delta G=0$ ) is drawn of hen lysozyme at pH 2 on the pressure-temperature plane. Finally, a three-dimensional free energy landscape $(\Delta G)$ is presented on the $p-T$ plane.

Corresponding author: Kazuyuki Akasaka, High Pressure Protein Research Center, Institute of Advanced Technology, Kinki University, 930 Nishimitani, Kinokawa, Wakayama 649-6493, Japan.

e-mail: akasaka@waka.kindai.ac.jp
Key words: hen lysozyme, high pressure fluorescence, high pressure NMR, thermodynamic stability on pressuretemperature axes, free energy landscape

Knowledge on thermodynamic stability of a globular protein forms a basis for understanding its function, folding as well as misfolding into amyloid fibrils ${ }^{1}$. In addition to the characterization of thermodynamic stability on the temperature axis ${ }^{2,3}$, the characterization of the same on the pressure axis is increasingly important in basic protein science ${ }^{4-6}$ as well as in the applied protein science ${ }^{7}$. Hen lysozyme, consisting of 129 amino acids with four disulfide bonds, is one of the most well characterized globular proteins both in structure and function. Hen lysozyme and its mutants have been widely used as a model system for studying enzyme function and protein folding ${ }^{8,9}$ as well as for studying amyloid fibril formation in recent years ${ }^{10-15}$. In the present study, pressure-induced equilibrium unfolding of hen lysozyme is carried out at $\mathrm{pH} 2$ using a high pressure fluorescence spectrometer which operates in the pressure range of $3 \sim 700 \mathrm{MPa}$ along with high pressure ${ }^{1} \mathrm{H}$ NMR spectroscopy which works in the pressure range of $3 \sim 400 \mathrm{MPa}$. Temperature was varied widely between $-10^{\circ} \mathrm{C}$ and $50^{\circ} \mathrm{C}$ so that a rather complete free energy landscape of hen lysozyme may be obtained on the pressure-temperature plane.

Figure 1 shows the three-dimensional structure of hen lysozyme (wild-type) in crystal (PDB ID: 135L) ${ }^{16}$, and a 


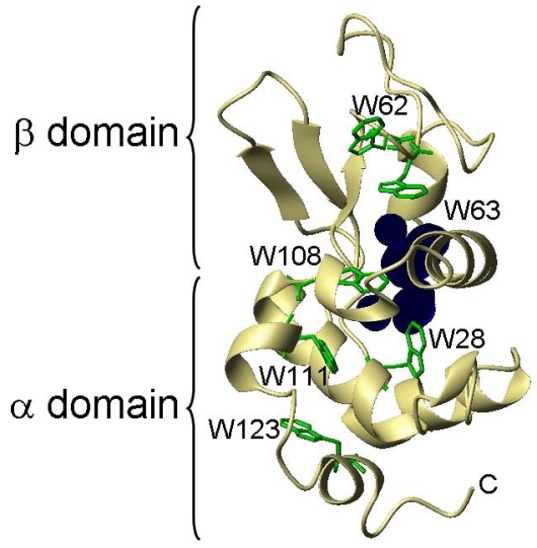

Figure 1 The structure of hen lysozyme in crystal (PDB ID; 135 L), which consists of two domains, $\alpha$ and $\beta$. The six tryptophan residues are colored green and the water-accessible internal cavity is shown by navy-spheres.

similar structure has been reported in solution ${ }^{17}$. The folded structure consists of two domains, $\alpha$ and $\beta$, the $\alpha$ domain having a large hydrophobic core with a large water-containing cavity ${ }^{17}$. There are in total six tryptophan residues in the molecule, two of which (Trp 62 and 63) are found in the $\beta$ domain and the rest are found in the $\alpha$ domain, of which Trp 28, 108 and 111 are close to the large cavity (Fig. 1). The fluorescence from the six Trp residues will be used for the thermodynamic analysis of equilibrium unfolding, while the side chain signals of ${ }^{1} \mathrm{H}$ NMR spectrum will be used to monitor the cooperative transition.

\section{Materials and methods}

\section{Materials}

Hen egg white lysozyme was obtained from Seikagaku Co. $(6 \times$ crystallized and lyophilized, Lot E40314) and was used without further purification. The protein solutions for NMR measurements were concentrated to $1.7 \mathrm{mM}$ in $50 \mathrm{mM}$ maleate buffer $\left(90 \%{ }^{1} \mathrm{H}_{2} \mathrm{O} / 10 \%{ }^{2} \mathrm{H}_{2} \mathrm{O}, \mathrm{pH} 2\right)$, which has one of the smallest $\Delta V$ values for the dissociation of the carboxyl group $\left(\Delta V=-5.1 \mathrm{ml} \mathrm{mol}^{-1}\right)^{18}$. Even so, the $\Delta V$ value predicts that the $\mathrm{pH}$ of the buffer may decrease as much as 0.6 unit at $700 \mathrm{MPa}$. Therefore, the effective $\mathrm{pH}$ of the solution in the entire range of pressure $(3 \sim 700 \mathrm{MPa})$ should vary between 2.0 and 1.4 .

\section{${ }^{1}$ H NMR measurements at variable pressure}

${ }^{1} \mathrm{H}$ one-dimensional variable-pressure NMR measurements of hen lysozyme were performed also at various temperatures in the pressure range between 3 and $400 \mathrm{MPa}$ at a ${ }^{1} \mathrm{H}$ frequency of $800.16 \mathrm{MHz}$ on a Bruker DRX-800 spectrometer ${ }^{20}$. At each pressure, intensity corrections are made for the pressure-induced compaction of the solvent water (e.g., by $\sim 9 \%$ at $300 \mathrm{MPa}, 298 \mathrm{~K})^{19}$. Data were processed with XWIN-NMR (Bruker BioSpin). A specially prepared pressure-resistive quartz cell (inner diameter $<1 \mathrm{~mm}$ ), which endures pressure up to $400 \mathrm{MPa}$ and gives a reasonably good spectral resolution, was chosen for this particular study. The detailed procedure for preparing the pressureresistive quartz cell for NMR is described in the literature ${ }^{21}$. ${ }^{1} \mathrm{H}$ chemical shifts were referenced to the methyl signal of 1,4-dioxane added internally $\left(\delta=3.70 \mathrm{ppm}\right.$ for $\left.{ }^{1} \mathrm{H}\right)$. For comparison, ${ }^{1} \mathrm{H}$ NMR experiments at $0.1 \mathrm{MPa}$ were also performed at $25^{\circ} \mathrm{C}, \mathrm{pH} 2$, in Shigemi tube $(5 \mathrm{~mm}$ outer diameter) with/without $8 \mathrm{M}$ urea at a ${ }^{1} \mathrm{H}$ frequency of 600.13 MHz using a 3-9-19 pulsed field gradient for water suppression on a Bruker AVANCE-600 spectrometer.

\section{Tryptophan fluorescence measurements at variable pressure}

Trp fluorescence spectra of hen lysozyme $(35 \mu \mathrm{M}$ or $0.5 \mathrm{mg} \mathrm{ml}^{-1}$ in $50 \mathrm{mM}$ maleate buffer, $\mathrm{pH}$ 2) were recorded on a fluorescence spectrophotometer (FP-6500, JASCO) with a high pressure chamber (Syn Corporation, Kyoto) within which a quartz cell containing $\sim 100 \mu$ l of the sample solution is placed, connected to a high pressure pump system (Techno Corporation, Hiroshima) using water as pressure mediator. Measurements were enabled in a wide pressure range between $3 \mathrm{MPa}$ and $700 \mathrm{MPa}, 3 \mathrm{MPa}$ being used instead of $0.1 \mathrm{MPa}$ to avoid any effect from air bubbles. The temperature of the high pressure chamber was controlled by circulating water-ethylene glycol 1-to-1 mixture to the highpressure sample-holding chamber. The excitation was made at $295 \mathrm{~nm}$ with a bandwidth of $3 \mathrm{~nm}$, and the emission from $310 \mathrm{~nm}$ to $450 \mathrm{~nm}$ was collected with a bandwidth of $10 \mathrm{~nm}$. The data were processed with Microcal Origin 6.0 (Microcal Software, Inc.).

\section{Analysis of high pressure fluorescence data}

We assume that the protein exists in the two-state equilibrium between the folded conformer $\mathrm{N}$ and the unfolded conformer U, namely

$$
\mathrm{N} \leftrightarrow \mathrm{U}
$$

with equilibrium constant $K$ dependent on pressure $p$ and temperature $T$. Furthermore, we assume that at a fixed temperature $T$; the wavelength of maximum fluorescence intensity $\lambda_{\max }$ at pressure $p$ is determined by the following relation

$$
\lambda_{\max }=f_{N} \lambda_{\max N}+f_{U} \lambda_{\max U}
$$

where $f_{N}$ represents the fraction of $\mathrm{N}, f_{U}$ represents the fraction of $\mathrm{U}, \lambda_{\max N}$ represents the wavelength of maximum fluorescence intensity for $\mathrm{N}$ and $\lambda_{\max U}$ represents the wavelength of maximum fluorescence intensity for $\mathrm{U}$. Then the equilibrium constant $K$ at any pressure $p$ will be determined experimentally by

$$
K=\frac{f_{U}}{f_{N}}=\frac{f_{U}}{1-f_{U}}=\frac{\lambda_{\max }-\lambda_{\max N}}{\lambda_{\max U}-\lambda_{\max }}
$$


from which the Gibbs free energy difference $\Delta G$ between $\mathrm{N}$ and $\mathrm{U}$ will be determined experimentally as a function of $p$ and $T$ by using the relation

$$
\Delta G=G_{U}-G_{N}=-R T \ln K
$$

In order to proceed further to determine thermodynamic parameters associated with the folding-unfolding transition as quantities independent of pressure and temperature, we must recourse to the theoretical expression of $\Delta G$ (eq. 5). Eq. 5 is expressed as a Taylor expansion of $\Delta G$ at a reference point $\left(p_{0}\right.$ and $\left.T_{0}\right)$ to the second order to $p$ and $T^{20}$

$$
\begin{aligned}
\Delta G= & \Delta G^{0}+\Delta V^{0}\left(p-p_{0}\right)+\frac{\Delta \kappa}{2}\left(p-p_{0}\right)^{2}-\Delta S_{0}\left(T-T_{0}\right) \\
& -\frac{\Delta C_{p}}{2 T_{0}}\left(T-T_{0}\right)^{2}+\Delta \alpha\left(p-p_{0}\right)\left(T-T_{0}\right)
\end{aligned}
$$

where $\Delta G^{0}$ is the Gibbs free energy difference of conformer $\mathrm{U}$ relative to $\mathrm{N}$ at a reference point $\left(p_{0}\right.$ and $\left.T_{0}\right), \Delta V^{0}$ is the change in partial molar volume of conformer $\mathrm{U}$ relative to $\mathrm{N}$ $\left(\Delta V^{0}=V_{\mathrm{U}}^{0}-V_{\mathrm{N}}^{0}\right)$ also at a reference point $\left(p_{0}\right.$ and $\left.T_{0}\right)$ and $\Delta \kappa$ is the isothermal compressibility change. $\Delta S_{0}$ is the entropy change at a reference point $\left(p_{0}\right.$ and $\left.T_{0}\right), \Delta C_{p}$ is the heat capacity change and $\Delta \alpha$ is the change in expansivity. In an experiment in which pressure is varied at a constant temperature, say $T=T_{\mathrm{x}}$, eq. 5 conforms to

$$
\begin{aligned}
\Delta G= & \Delta G^{0}{ }_{x}+\Delta V^{0}\left(p-p_{0}\right)+\frac{\Delta \kappa}{2}\left(p-p_{0}\right)^{2} \\
& +\Delta \alpha\left(p-p_{0}\right)\left(T_{x}-T_{0}\right)
\end{aligned}
$$

where $\Delta G^{0}{ }_{x}$ is the free energy difference extrapolated to a reference pressure $(0.1 \mathrm{MPa})$ at $T_{x}$, and the slope against $p$ gives the volume change at $T_{x}$. In the further analysis, we neglect the compressibility term $\Delta \kappa\left(p-p_{0}\right)^{2} / 2$, as is often found permissible for many globular proteins ${ }^{22}$, whence we obtain the expression for the volume difference as a temperature-dependent quantity,

$$
\Delta V=V_{U}-V_{N}=\Delta V_{0}+\Delta \alpha\left(T-T_{0}\right)
$$

where the subscript $\mathrm{x}$ is eliminated from $T$. Then the change in the wavelength of maximum fluorescence intensity $\left(\lambda_{\max }\right)$ can be expressed by combining eq. 2, 3, 4 and 6 .

$$
\lambda_{\max }=\frac{\lambda_{\text {max }}+\lambda_{\text {max }} \exp \left[-\left\{\Delta G^{0}+\Delta V^{0}\left(p-p_{0}\right)+\Delta \alpha\left(p-p_{0}\right)\left(T-T_{0}\right)\right\} / R T\right]}{1+\exp \left[-\left\{\Delta G^{0}+\Delta V^{0}\left(p-p_{0}\right)+\Delta \alpha\left(p-p_{0}\right)\left(T-T_{0}\right)\right\} / R T\right]}
$$

At the midpoint of transition between $\mathrm{N}$ and $\mathrm{U}$, where $\Delta G=0$ and $f_{N}=f_{U}$, we obtain the relations

$$
\begin{aligned}
& p_{m}=\Delta G^{0} / \Delta V \\
& \Delta G=\Delta H_{m}\left(1-\frac{T}{T_{m}}\right)+\Delta C_{p}\left\{T-T_{m}-T \ln \left(\frac{T}{T_{m}}\right)\right\} \\
& \Delta S_{m}=\frac{\Delta H_{m}}{T_{m}}
\end{aligned}
$$

where $T_{m}, p_{m}, \Delta H_{m}, \Delta S_{m}$ and $\Delta C_{p}$ represent the temperature at the midpoint $\left(T_{m}\right)$ and pressure at the midpoint $\left(p_{m}\right)$ of transition between $\mathrm{N}$ and $\mathrm{U}$, the unfolding enthalpy change at $T_{m}$, the unfolding entropy change at $T_{m}$ and the unfolding heat capacity change, respectively.

\section{Experimental results}

\section{${ }^{1} \mathrm{H}$ NMR spectra at 0.1 400 MPa}

${ }^{1} \mathrm{H}$ one-dimensional NMR measurements were carried out on hen lysozyme ( $\mathrm{pH} 2$ ) at varying pressures up to $400 \mathrm{MPa}$, the highest pressure available in the current high pressure NMR system at $800 \mathrm{MHz}$ at various temperatures. Except at subzero temperatures, e.g. at $-5^{\circ} \mathrm{C}$, we could not attain full unfolding even at $400 \mathrm{MPa}$. In Figure $2 \mathrm{~A}$, the ${ }^{1} \mathrm{H} \mathrm{NMR}$

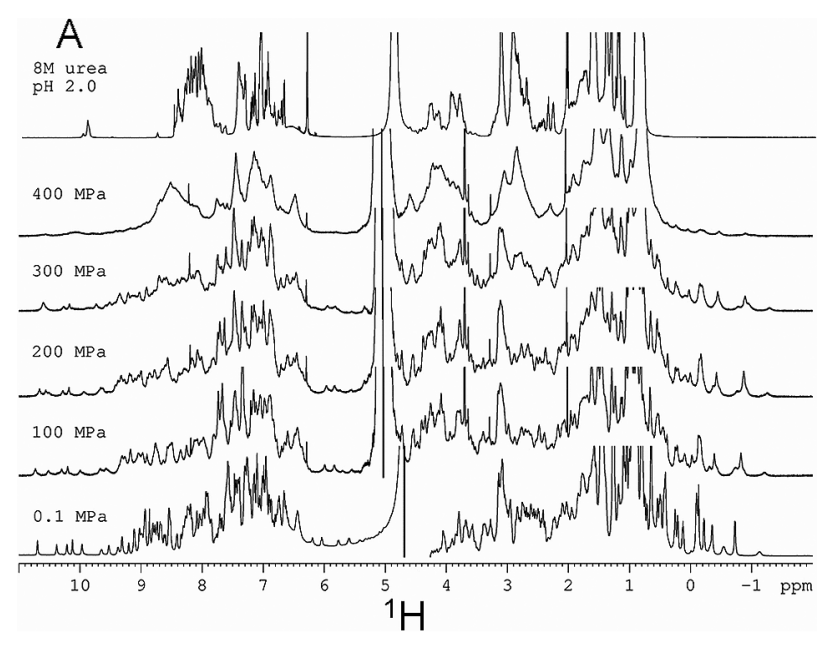

B

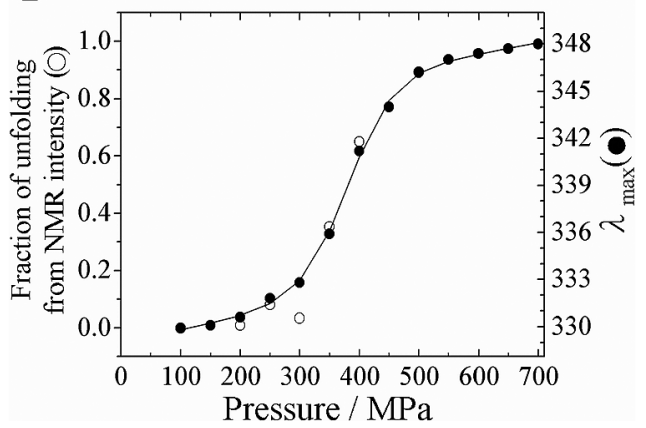

Figure 2 (A) ${ }^{1} \mathrm{H}$ NMR spectra $(800 \mathrm{MHz})$ of hen lysozyme recorded at various pressures from $100 \mathrm{MPa}$ to $400 \mathrm{MPa}$ at $-5^{\circ} \mathrm{C}$. The spectrum at $0.1 \mathrm{MPa}$ (bottom) was obtained at $25^{\circ} \mathrm{C}$ at $600 \mathrm{MHz}$. The spectrum at $0.1 \mathrm{MPa}$ (top) was also obtained at $25^{\circ} \mathrm{C}$, but in the presence of $8 \mathrm{M}$ urea. Chemical shifts are referenced to dioxane $\delta=$ $3.70 \mathrm{ppm}$. All the protein solutions were prepared in $50 \mathrm{mM}$ maleate buffer, $90 \%{ }^{1} \mathrm{H}_{2} \mathrm{O} / 10 \%{ }^{2} \mathrm{H}_{2} \mathrm{O}(\mathrm{pH} 2)$. (B) The fraction of unfolding against pressure as estimated from the fractional decrease of the combined intensity of high-field shifted methyl ${ }^{1} \mathrm{H}$ NMR signals of Leu17, Thr51, Ile56, Ile88 and Ile98 $(\delta=-0.3 \sim 0.8 \mathrm{ppm})^{26}$ (open circles) and from the red shift of the wavelength of maximum fluorescence emission $\left(\lambda_{\max }\right)$ (closed circles). The solid curve is drawn by best-fitting the fluorescence data to eq. 8 . 
spectra recorded at $-5^{\circ} \mathrm{C}$ above $100 \mathrm{MPa}$ only to avoid freezing are shown. The spectrum at $0.1 \mathrm{MPa}$ was recorded at $25^{\circ} \mathrm{C}$ and is shown in Figure $2 \mathrm{~A}$ (bottom). The spectrum for the "fully unfolded" structure was recorded also at $25^{\circ} \mathrm{C}$ at $0.1 \mathrm{MPa}$ in the presence of $8 \mathrm{M}$ urea and is also shown in Figure 2A (top).

Figure $2 \mathrm{~A}$ shows that the spectrum at $100 \mathrm{MPa}$ is essentially the same as that at $0.1 \mathrm{MPa}\left(25^{\circ} \mathrm{C}\right)$ in chemical shifts except for significant line broadening. This result indicates that hen lysozyme at $-5^{\circ} \mathrm{C}$ and at $100 \mathrm{MPa}$ retains almost the same "folded" structure as that at $0.1 \mathrm{MPa}$ at $25^{\circ} \mathrm{C}$, which is expected to be close to that in Figure 1 . The broader signals at $-5^{\circ} \mathrm{C}$ and at $100 \mathrm{MPa}$ would be largely attributable to the lower spectral resolution of the particular pressure-resistive cell used, although the possibility of extra broadening due to partial hydration of the protein matrix ${ }^{23,24}$ may not be denied.

As the pressure is increased above $100 \mathrm{MPa}$, the characteristic spectral features of the folded structure are gradually lost and replaced by a featureless spectrum typical for an unfolded conformer with disordered and hydrated polypeptide chain ${ }^{25}$, similar to that in $8 \mathrm{M}$ urea (Fig. 2A (top)) except for line broadening. In particular, the $\varepsilon$-proton signals of all the six Trp residues are observed and well dispersed at 9.4, 10.1, 10.2, 9.5, 10.4 and $10.7 \mathrm{ppm}$, which are assignable to $\operatorname{Trp} 28,62,63,108,111$ and 123 , respectively ${ }^{23,26}$, showing the characteristic folded structure of hen lysozyme at low pressure. At $400 \mathrm{MPa}$, however, all these signals are lost and replaced by new signals at $\sim 10$ ppm typical for $\varepsilon$-protons of solvent-exposed Trp residues ${ }^{25}$, giving evidence that all the six Trp residues are exposed to the solvent. Also the extremely high-field shifted methyl proton signals $(<0 \mathrm{ppm})$, representing another characteristic signature of the folded hen lysozyme (Fig. 1), are nearly completely lost at $400 \mathrm{MPa}$, which must have merged into the biggest resonance peak at $\sim 0.9 \mathrm{ppm}^{25}$. All the spectral changes are reversible with pressure. These observations clearly indicate that the folded structure is almost fully lost as the pressure is increased to $400 \mathrm{MPa}$.

We take the combined intensity $(I)$ of the high-field shifted methyl proton signals at $-0.8 \sim 0.3 \mathrm{ppm}$ in Figure $2 \mathrm{~A}$ (assignable to Leu17, Thr51, Ile56, Ile88 and Ile98) ${ }^{26}$ at pressure $p$ relative to its initial intensity $\left(I_{0}\right)$ at $100 \mathrm{MPa}$, after correcting the intensity due to the compression of the solvent water (See Materials and Methods), as representing the folded fraction $\left(f_{\mathrm{N}}\right)$ of hen lysozyme at $-5^{\circ} \mathrm{C}$. In Figure $2 \mathrm{~B}$, we plot the fraction of the unfolded conformer $\mathrm{U}$ $\left(f_{\mathrm{U}}=1-f_{\mathrm{N}}\right)$ as a function of pressure (open circle). In the same figure, we also plot the change in the wavelength of maximum fluorescence intensity $\left(\lambda_{\max }\right)$ measured under the same condition ( $\mathrm{pH} 2$, at $-5^{\circ} \mathrm{C}$, except for the concentration) up to $700 \mathrm{MPa}$ (closed circle). The good coincidence of the two plots certifies that the change in $\lambda_{\text {max }}$ of Trp fluorescence represents the fraction of unfolding as correctly as predicted by the ${ }^{1} \mathrm{H}$ NMR signal intensity. Furthermore, the solid curve in Figure 2B represents the best-fit of eq. 8, based on the two-state equilibrium of eq. 1 , to the change in the wavelength of maximum fluorescence intensity $\left(\lambda_{\max }\right)$. The coincidence is excellent, which prompts us to use the wavelength of maximum fluorescence intensity $\left(\lambda_{\max }\right)$ in conjunction with eq. 8 to obtain thermodynamic parameters associated to the folding-unfolding transition of hen lysozyme at $\mathrm{pH} 2$. Thus in the following section, we use the fluorescence data carried out up to $700 \mathrm{MPa}$, which realized complete unfolding at all temperatures studied.

\section{Trp fluorescence spectra at 0.1 700 MPa}

As hen lysozyme is highly resistive to pressure even at pH 2 and full unfolding is hardly attainable at $400 \mathrm{MPa}$, the highest pressure available in our current high pressure NMR system $^{20,21}$ at normal temperatures, we now turn to highpressure fluorescence spectroscopy ${ }^{27}$ with which we can reach $700 \mathrm{MPa}$.

Figure 3 (A-G left) compiles the fluorescence spectral data from six Trp residues of hen lysozyme $(35 \mu \mathrm{M}$ in $50 \mathrm{mM}$ maleate buffer, $\mathrm{pH} 2$ ), measured as a function of pressure from $3 \mathrm{MPa}$ to $700 \mathrm{MPa}$ at different temperatures $\left(-5^{\circ} \mathrm{C},-10^{\circ} \mathrm{C}, 5^{\circ} \mathrm{C}, 15^{\circ} \mathrm{C}, 25^{\circ} \mathrm{C}, 40^{\circ} \mathrm{C}\right.$ and $\left.50^{\circ} \mathrm{C}\right)$. In all cases, the fluorescence spectrum changes with pressure both in intensity and wavelength, which are fully reversible with pressure with respect to the maximum wavelength of emission $\left(\lambda_{\max }\right)$ but less reversible $(\sim 80 \%)$ with respect to the intensity of emission. The lack of full reversibility is often encountered in high-pressure fluorescence experiments owing to some technical reasons. On the other hand, the shift in $\lambda_{\max }$ of Trp fluorescence is considered to represent correctly the change in the microenvironment of the tryptophan ring $^{22}$ : The blue shift $\left(\lambda_{\max } \sim 330 \mathrm{~nm}\right)$ indicates that the Trp ring is in the non-polar environment or buried in the hydrophobic core, while the red shift $\left(\lambda_{\max } \sim 350-355 \mathrm{~nm}\right)$ indicates that the Trp ring is in the polar environment or exposed to the solvent water ${ }^{27}$. Although at $700 \mathrm{MPa}$ below $\sim 5^{\circ} \mathrm{C}$ water is expected to go into ice VI, the smooth transitions in Figure 3A, B and C suggest that the solution went into the super-cooled state.

Figure 3 (A-G right) plots the maximum emission wavelength $\left(\lambda_{\max }\right)$ against pressure at all temperatures studied. At all temperatures, $\lambda_{\max }$ stayed initially within $330 \sim 335 \mathrm{~nm}$, showing that $\operatorname{Trp}$ residues are almost fully buried in the folded conformation. Finally at $700 \mathrm{MPa}, \lambda_{\max }$ shifted to $349 \sim 350 \mathrm{~nm}$ at all temperatures, showing that all the six Trp residues become exposed to the solvent in accordance with the high pressure NMR result (Fig. 2). Therefore, we conclude that the protein is totally unfolded at $700 \mathrm{MPa}$. In Figure 3 right, we plot $\lambda_{\max }$ as a function of pressure at all temperatures studied, which presumably represents transitions of hen lysozyme from the folded $(\mathrm{N})$ to the unfolded (U) conformer. 

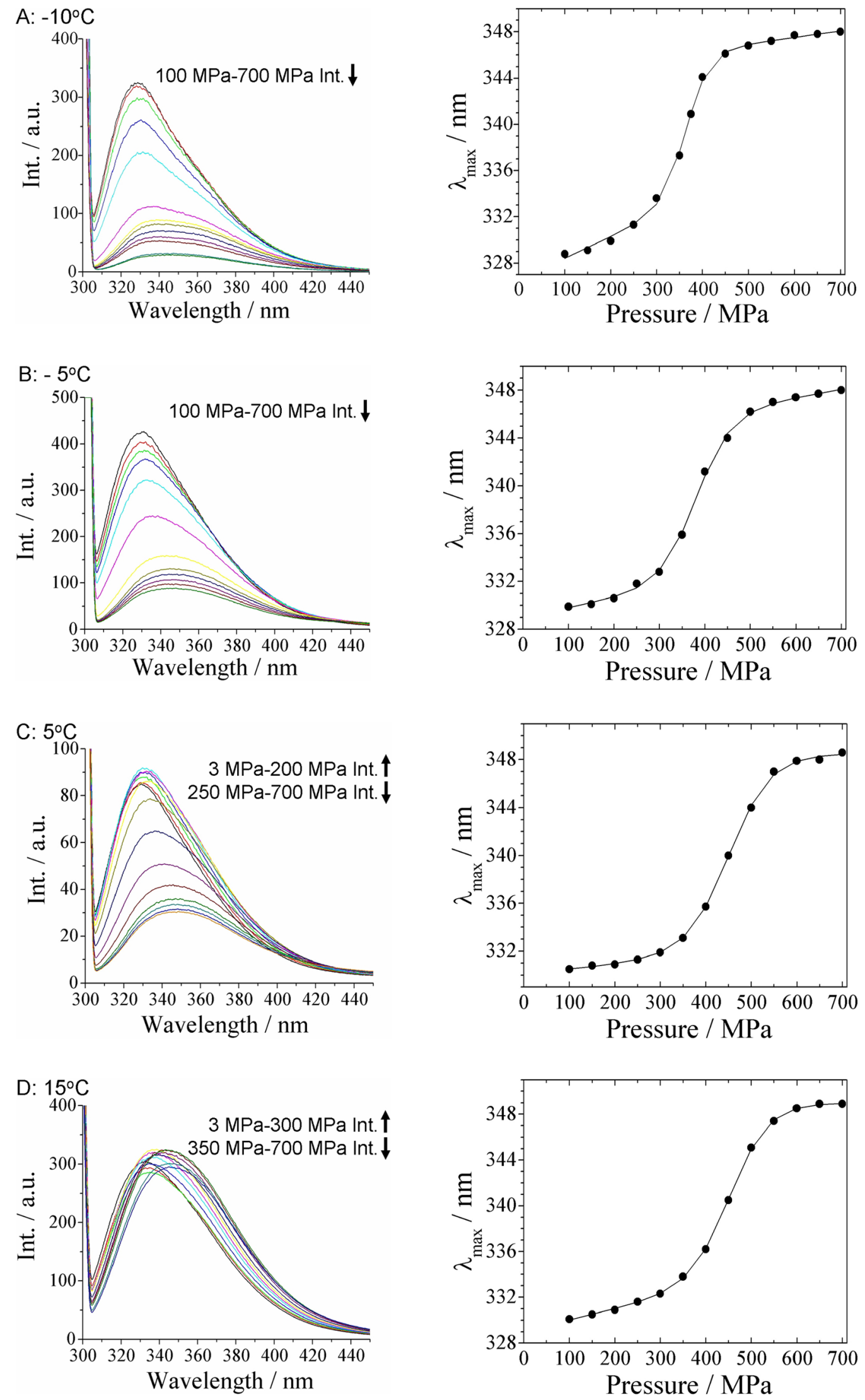

Figure 3 (A-D) 

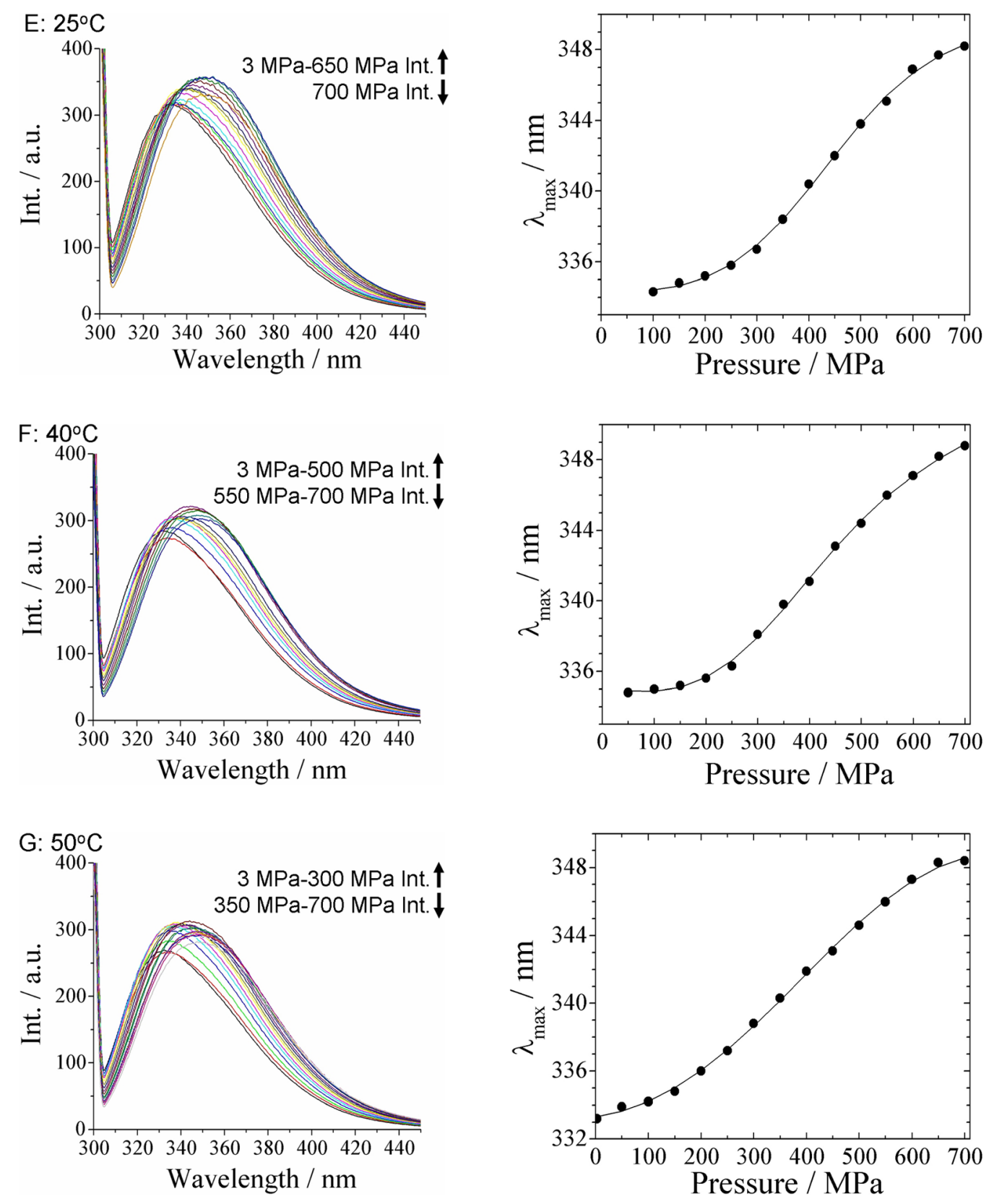

Figure 3 (E-G)

Figure 3 Trp fluorescence changes of hen lysozyme at $\mathrm{pH} 2$ as a function of pressure at various temperatures. (A-G) (Left) Overlay of fluorescence spectra of hen lysozyme recorded as a function of pressure at various temperatures. The upward and downward arrows indicate whether the fluorescence intensity is increased or decreased with increasing pressure in the pressure range indicated. (A-G) (Right) Plots of the wavelength of maximum fluorescence intensity $\left(\lambda_{\max }\right)$ as a function of pressure at various temperatures. The solid curves are the best-fit of eq. 8 to $\lambda_{\max }$, giving $\Delta G^{0}$ and $\Delta V$ (eq. 7) values at different temperatures, which are listed in Table 1.

\section{Thermodynamic analysis and discussion}

\section{Volume and expansivity changes}

We assume the two-state transition between $\mathrm{N}$ and $\mathrm{U}$ (eq. 1) and best-fit the observed changes in the wavelength of maximum fluorescence intensity $\left(\lambda_{\max }\right)$ in Figure 3 (right) with eq. 8, which gives $\Delta V$ (eq. 7) and $\Delta G^{0}$ values listed in Table 1, together with pressures at the midpoint of transition $p_{m}$ (eq. 9). In Table 1 , we note that $p_{m}$ ranges from $250 \mathrm{MPa}$ $\left(50^{\circ} \mathrm{C}\right)$ to $453 \mathrm{MPa}\left(5^{\circ} \mathrm{C}\right)$, revealing a relatively high stability of hen lysozyme against pressure denaturation even at low $\mathrm{pH}$. The stability extrapolated to $0.1 \mathrm{MPa}\left(\Delta G^{0}\right)$ shows an increasing trend by lowering temperature, but the values may not be as reliable as $\Delta V$ in the present case, because $0.1 \mathrm{MPa}$ is far from $p_{m}$ and no reliable data points are available to $0.1 \mathrm{MPa}$. 
Table 1 Thermodynamic parameters for unfolding of hen lysozyme determined from Trp fluorescence experiments

\begin{tabular}{cccc}
\hline$T\left({ }^{\circ} \mathrm{C}\right)$ & $\Delta G^{0}\left(\mathrm{~kJ} \mathrm{~mol}^{-1}\right)^{a}$ & $\Delta V\left(\mathrm{~kJ} \mathrm{~mol}^{-1}\right)^{b}$ & $p_{m}(\mathrm{MPa})^{c}$ \\
\hline-10 & $31.5 \pm 3.8$ & $-85.9 \pm 3.8$ & 366.7 \\
-5 & $22.1 \pm 2.6$ & $-58.2 \pm 6.7$ & 379.7 \\
5 & $23.1 \pm 1.5$ & $-51.0 \pm 3.5$ & 452.9 \\
15 & $25.7 \pm 1.1$ & $-56.2 \pm 2.4$ & 357.3 \\
25 & $9.5 \pm 3.4$ & $-22.4 \pm 9.3$ & 424.1 \\
40 & $7.6 \pm 2.8$ & $-23.4 \pm 8.2$ & 324.8 \\
50 & $4.2 \pm 3.1$ & $-16.8 \pm 11.8$ & 250.0 \\
\hline${ }^{a}$ Gibbs free energy change at $0.1 \mathrm{MPa}$ calcurated with eq. 8. \\
${ }^{b}$ Partial molar volume change $\left(\Delta V=\Delta V^{0}+\Delta \alpha\left(T-T^{0}\right)\right)$ calculated \\
with eq. 8. \\
${ }^{c}$ The denatured temperature
\end{tabular}

Figure 4 gives the plot of $\Delta V=V_{U}-V_{N}$, as obtained from the fit in Figure 3 (right) against temperature, which are all negative within the temperature range studied $\left(-10^{\circ} \mathrm{C} \sim\right.$ $50^{\circ} \mathrm{C}$ ), but with a significant temperature dependence. From the slope, we obtain as the expansivity change upon unfolding $\Delta \alpha=1.07 \mathrm{ml} \mathrm{mol}^{-1} \mathrm{deg}^{-1}$ in eq. 7 . This value is comparable to those in staphylococcal nuclease $\left(1.33 \mathrm{ml} \mathrm{mol}^{-1}\right.$ $\left.\mathrm{deg}^{-1}\right)^{28}$ as well as in metmyoglobin $\left(1.8 \mathrm{ml} \mathrm{mol}^{-1} \mathrm{deg}^{-1}\right)^{4}$ and in ribonuclease $\mathrm{A}\left(1.32 \mathrm{ml} \mathrm{mol}^{-1} \mathrm{deg}^{-1}\right)^{29}$. The positive value of $\Delta \alpha$ is taken to indicate the increased thermal volume due to the increased exposure of the polypeptide chain upon unfolding ${ }^{22}$.

\section{Stability and heat capacity changes}

In Figure 5, we plotted the experimentally determined values of $\Delta G$ (eq. 4) against temperature at constant pressures, which depict concave features at all pressures studied. Data are limited to above $200 \mathrm{MPa}$, as no significant fraction unfolds in the lower pressure range to give sufficiently reliable $\Delta G$ values below $200 \mathrm{MPa}$. The plots were best-fitted with eq. 10, giving parameters of $\Delta C_{p}, T_{S}$ (the temperature for $\Delta S=0$ ), $T_{m}, \Delta H_{m}$ and $\Delta S_{m}$ (for both heat and cold denaturations) as summarized in Table 2. The Gibbs free energy changes $(\Delta G)$ are fitted reasonably well with a single positive $\Delta C_{p}$ value at each pressure, covering both the cold denaturation and heat denaturation ranges. In general, a positive $\Delta C_{p}$ upon unfolding is accepted as due to the exposure of nonpolar amino acid groups into the solvent water ${ }^{2}$. In accordance with this, $\Delta H_{m}$ for heat denaturation increases with increasing $T_{m}$. Interestingly, while the stability is found to decrease with pressure, $T_{S}$, the temperature of maximum stability (the temperature for $\Delta S=0$ ) increases with increasing pressure.

\section{Phase diagram and free energy landscape}

Figure 6 shows the phase diagram (for $\Delta G=0$ ) of hen lysozyme for the first time in aqueous environment on the pressure-temperature plane. So far, the thermodynamic stability on the temperature-pressure plane in aqueous environment has been reported for a limited number of proteins,

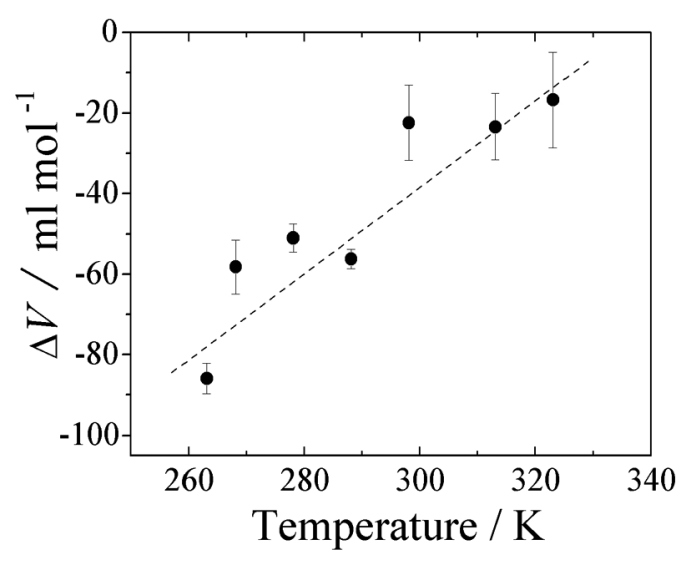

Figure 4 Plot of the change in partial molar volume $\Delta V$ on unfolding against temperature. Best-fit to eq. 7 gives a change in expansivity $\Delta \alpha$ on unfolding $(260 \sim 320 \mathrm{~K}, \mathrm{pH} 2)$ to be $1.07 \mathrm{ml} \mathrm{mol}^{-1} \mathrm{deg}^{-1}$.

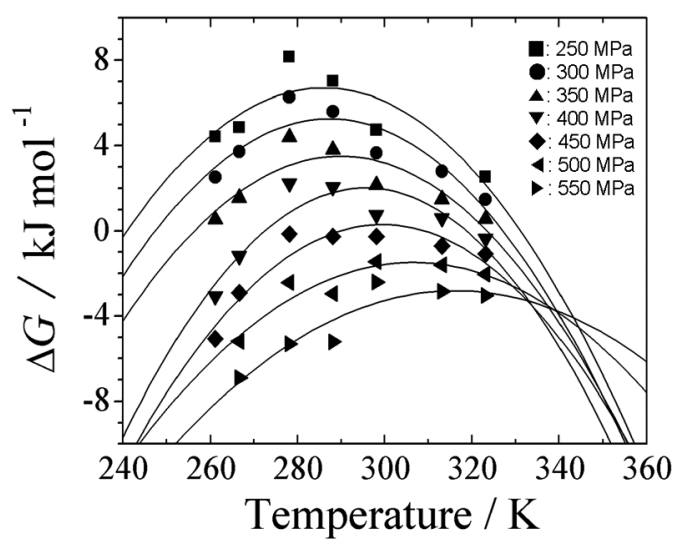

Figure 5 Plots of the change in free energy $\Delta G$ on unfolding for hen lysozyme ( $\mathrm{pH} 2)$ at various pressures. The solid lines show best-fit of eq. 10 to the experimental points, with melting temperature $\left(T_{m}\right)$, enthalpy change at $T_{m}\left(\Delta H_{m}\right)$ and heat capacity change on unfolding $\left(\Delta C_{p}\right)$ as fitting parameters listed in Table 2.

including metmyoglobin ${ }^{4}$ chymotrypsinogen ${ }^{30}$, ribonuclease $\mathrm{A}^{29}$ and Staphylococcal nuclease $\mathrm{e}^{28,31-32}$. In these proteins, except for chymotrypsinogen which clearly gives a region of pressure-induced folding at elevated temperature ${ }^{30}$, an ellipsoid type pattern like that in Figure 6 with no regions of pressure-induced folding has been commonly observed, although the individual pattern is characteristic of each $\operatorname{protein}^{33}$.

In Figure 7, we draw the energy landscape of hen lysozyme at low $\mathrm{pH}$ on pressure and temperature axes based on eq. 5 on the approximation of null isothermal compressibility change $\Delta \kappa$ within the pressure range studied. This will provide the basis for studying hen lysozyme at low $\mathrm{pH}$ by varying temperature and/or pressure. 
Table 2 Thermodynamic parameters for heat and cold denaturation of hen lysozyme

\begin{tabular}{|c|c|c|c|c|c|c|}
\hline \multicolumn{2}{|c|}{$P(\mathrm{MPa})$} & $\Delta H_{m}\left(\mathrm{~kJ} \mathrm{~mol}^{-1}\right)^{a}$ & $\Delta S_{m}\left(\mathrm{~J} \mathrm{~mol}^{-1} \mathrm{~K}^{-1}\right)^{b}$ & $\Delta C_{p}\left(\mathrm{~kJ} \mathrm{~mol}^{-1} \mathrm{~K}^{-1}\right)^{c}$ & $T_{m}(\mathrm{~K})^{d}$ & $T_{s}(\mathrm{~K})^{e}$ \\
\hline \multirow[t]{2}{*}{250} & Heat & $95.1 \pm 14.2$ & $287.0 \pm 14.5$ & $1.9 \pm 0.8$ & $331.4 \pm 3.0$ & 286 \\
\hline & Cold & $-77.4 \pm 10.6$ & $-319.4 \pm 14.3$ & & $242.3 \pm 9.6$ & \\
\hline \multirow[t]{2}{*}{300} & Heat & $83.9 \pm 7.5$ & $256.3 \pm 8.6$ & $1.9 \pm 0.6$ & $327.4 \pm 4.2$ & 287 \\
\hline & Cold & $-70.2 \pm 8.3$ & $-282.8 \pm 8.5$ & & $248.2 \pm 2.0$ & \\
\hline \multirow[t]{2}{*}{350} & Heat & $66.3 \pm 5.6$ & $204.7 \pm 6.0$ & $1.8 \pm 0.5$ & $323.9 \pm 2.2$ & 290 \\
\hline & Cold & $-56.4 \pm 13.0$ & $-219.6 \pm 13.8$ & & $256.8 \pm 4.5$ & \\
\hline \multirow[t]{2}{*}{400} & Heat & $54.2 \pm 14.0$ & $170.0 \pm 14.6$ & $1.8 \pm 0.6$ & $318.8 \pm 4.1$ & 296 \\
\hline & Cold & $-48.5 \pm 6.0$ & $-178.0 \pm 6.3$ & & $272.5 \pm 1.8$ & \\
\hline
\end{tabular}

${ }^{a}$ Unfolding entharpy at $T_{m}$

${ }^{b}$ Unfolding entropy at $T_{m}$

${ }^{c}$ Unfolding heat capacity at $T_{m}$

${ }^{d}$ Denaturation temperature

${ }^{e}$ Temperature for maximum stability $((\partial \Delta G / \partial T)=\Delta S=0)$

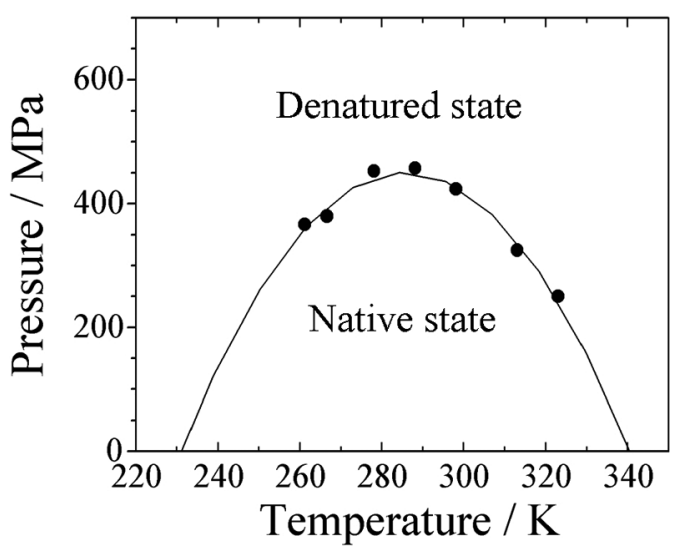

Figure 6 The phase diagram of hen lysozyme at $\mathrm{pH} 2$ as obtained by fluorescence measurements. Plot of $p_{m}$ (pressure at the midpoint of transition between $\mathrm{N}$ and $\mathrm{U}$ or half-denaturation) obtained from eq. 9 against $T_{m}$. The solid curve represents the best-fit of eq. 5 for $\Delta G=0$ to the experimental points.

\section{Concluding remark}

Since hen lysozyme ishighly resistive to pressure, thermodynamic unfolding studies on pressure axis have been carried out in the presence of denaturants $\mathrm{s}^{34}$. In the present study, the study on the thermodynamic stability was carried out on the pressure and temperature axes on hen lysozyme in an aqueous environment at low $\mathrm{pH}$. This was made possible by the use of a high pressure fluorescence spectrometer developed in our laboratory that operates up to $700 \mathrm{MPa}$, the details of which will be published elsewhere. The knowledge and the method presented here will serve as a basis for studying dynamics and folding of hen lysozyme as a whole, but will also provide information as to the condition for the formation of amyloid fibrils or insoluble aggregates in a wider perspective. In general, the extension of thermodynamic characterization of globular proteins to pressure axis will increase our understanding of proteins as well as our ability for manipulating conformational states of proteins for practical purposes.

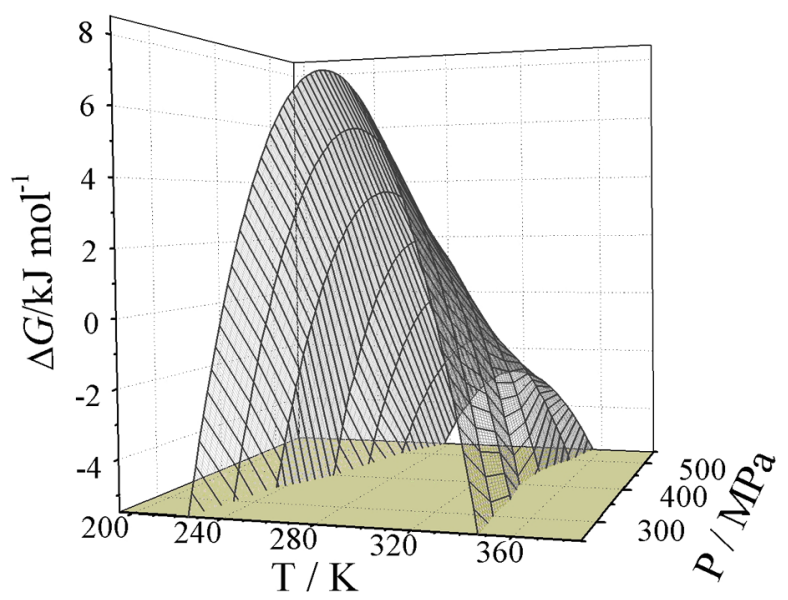

Figure 7 Three-dimensional free-energy landscape of hen lysozyme at $\mathrm{pH} 2$ in the range of pressure from $250 \mathrm{MPa}$ to $550 \mathrm{MPa}$ and temperature from $200 \mathrm{~K}$ to $380 \mathrm{~K}$, drawn as overlay of eq. 5 at various pressures.

\section{Acknowledgements}

This work has been supported by the Academic Frontier Program of the Ministry of Education, Culture, Sports, Science and Technology of Japan. Akihiro Maeno is a Junior Research Associate of RIKEN under the guidance of Dr. Yoshitsugu Shiro at SPring-8 Center.

\section{References}

1. Moriarty, D. F. \& Colon, W. Structural intermediates of globular proteins as precursors to amyloid formation. Amyloid Proteins 1 (Jen D. Sipe ed.) vol. 1, (Wiley-VCH, 2005).

2. Privolov, P. L. Thermodynamic problems of protein structure. Annu. Rev. Biophys. Chem. vol. 18, 47-69 (1989).

3. Privolov, P. L. Cold denaturation of proteins. Crit Rev Biochem Mol Biol. 25, 281-305 (1990).

4. Zipp, A. \& Kauzmann, W. Pressure denaturation of metmyoglobin. Biochemistry 12, 4217-4228 (1973).

5. Nash, D. P. \& Jonas, J. Structure of pressure-assisted cold denatured lysozyme and comparison with lysozyme folding intermediates. Biochemistry 36, 14375-14383 (1997). 
6. Akasaka, K. Probing conformational fluctuation of proteins by pressure perturbation. Chem. Rev. 106, 1814-1835 (2006).

7. Hayashi, R. Trends in high pressure bioscience and biotechnology. Progress in Biotechnology vol. 19 (Elsevier, 2002).

8. Matagne, A. \& Dobson, C. M. The folding process of hen lysozyme: a perspective from the 'new view'. Cell Mol Life Sci. 54, 363-371 (1998).

9. Radford, S. E., Dobson, C. M. \& Evans, P. A. The folding of hen lysozyme involves partially structured intermediates and multiple pathways. Nature 23, 302-307 (1992).

10. Frare, E., Plverino de Laureto, P. Zurdo, J., Dobson, C. M. \& Fontana, A. A highly amyloidogenic region of hen lysozyme. J. Mol. Biol. 340, 1153-1165 (2004).

11. Arnaudov, L. N. \& Renko de Vries. Thermally induced fibrillar aggregation of hen Egg white lysozyme. Biophys. $J$. 88, 515-526 (2005).

12. Mishra, R., Sörgjerd, K., Nyström, S., Nordigården, A., Yu, Y. \& Hammarström, P. Lysozyme amyloidogenesis is accelerated by specific nicking and fragmentation but decelerated by intact protein binding and conversion. J. Mol. Biol. 366, 1029-1044 (2007).

13. Sasaki, K., Nakatsuka, K., Hayashi, I., Shah, B. R., Morimoto, K. \& Akasaka, K. Efficient conversion of intact hen lysozyme into amyloid fibrils by seeding. J. Biol. Macromol. 8, 11-18 (2008).

14. Akasaka, K., Abdul Latif, A., Nakamura, A., Matsuo, K., Tachibana, H. \& Gekko, K. Amyloid protofibril is highly voluminous and compressible. Biochemistry 46, 10444-10450 (2007).

15. Abdul Latif, A., Kono, R., Tachibana, H. \& Akasaka, K. Kinetic analysis of amyloid protofibril dissociation and volumetric properties of the transition state. Biophys. J. 92, 323329 (2007)

16. Blake, C. C., Koenig, D. F., Mair, G. A., North, A. C, Phillips, D. C. \& Sarma, V. R. Structure of hen egg-white lysozyme. A three-dimensional Fourier synthesis at 2 angstrom resolution. Nature 22, 757-761 (1965)

17. Schwalbe, H., Grimshaw, S. B., Spencer, A., Buck, M., Boyd, J., Dobson, C. M., Redfield, C. \& Smith, L. J. A refined solution structure of hen lysozyme determined using residual dipolar coupling data. Protein Sci. 10, 677 (2001).

18. Kitamura, Y. \& Itoh, T. Reaction volume of protonic ionization for buffering agents. Prediction of pressure dependence of $\mathrm{pH}$ and $\mathrm{pOH}$. Journal of Solution Chemistry 16, 715-726 (1987).

19. Bridgman, P. W. Water in the liquid and five solid forms under pressure. Proc. Am. Acad. Arts Sci. 47, 441-558 (1912).

20. Akasaka, K. \& Yamada, H. On-Line cell high pressure nuclear magnetic resonance technique: application to protein studies, in Methods in Enzymology, vol. 338: Nuclear Magnetic
Resonance of Biological Macromolecules, Part A (James, T. L., et al., eds.), pp. 134-158 (Academic Press, New York, 2001).

21. Yamada, H., Nishikawa, K., Honda, M., Shimura, T., Tabayashi, K. \& Akasaka, K. Pressure-resisting cell for highpressure, high-resolution nuclear magnetic resonance measurements at very high magnetic fields. Rev. Sci. Instrum. 72, 14631471 (2001).

22. Royer, C. A. Probing protein folding and conformational transitions with fluorescence. Chem. Rev. 106, 1769-1784 (2006).

23. Kamatari, Y. O., Yamada, H., Akasaka, K., Jones, J. A., Dobson, C. M \& Smith, L. J. Response of native and denatured henlysozyme to high pressure studied by ${ }^{15} \mathrm{~N} /{ }^{1} \mathrm{H}$ NMR spectroscopy. Eur. J. Biochem. 268, 1782-1793 (2001).

24. Refaee, M., Tezuka, T., Akasaka, K. \& Williamson, M. P. Pressure-dependent changes in the solution structure of hen egg-white lysozyme. J. Mol. Biol. 327, 857-865 (2003).

25. Wishart, D. S., Bigam, C. G., Holm, A., Hodges, R. S. \& Sykes, B. D. ${ }^{1} \mathrm{H},{ }^{13} \mathrm{C}$ and ${ }^{15} \mathrm{~N}$ random coil NMR chemical shifts of the common amino acids. I. Investigations of nearestneighbor effects. J. Biomol. NMR 5, 67-81 (1995).

26. Redfield, C. \& Dobson, C. M. Sequential ${ }^{1} \mathrm{H}$ NMR assignments and secondary structure of hen egg white lysozyme in solution. Biochemistry 27, 122-136 (1988).

27. Lakowicz, J. R. Principles of Fluorescence Spectroscopy (Third Edition) (Springer, 2006).

28. Lassalle, M. W., Yamada, H. \& Akasaka, K. The pressuretemperature free energy-landscape of Staphylococcal nuclease monitored by ${ }^{1}$ H NMR. J. Mol. Biol. 298, 293-302 (2000).

29. Brandts, J. F. Olivera, R. J. \& Westort, C. Thermodynamics of protein denaturation. Effect of pressure on the denaturation of ribonuclease A. Biochemistry 9, 1038-1047 (1970).

30. Hawley, S. A. Reversible pressure-temperature denaturation of chymotrypsinogen. Biochemistry 10, 2436-2442 (1971).

31. Panick, G., Malessa, R., Winter, R., Rapp, G., Frye, K. J. \& Royer, C. A. Structural characterization of the pressuredenatured state and unfolding/refolding kinetics of staphylococcal nuclease by synchrotron small-angle X-ray scattering and Fourier-transform infrared spectroscopy. J. Mol. Biol. 16, 389-402 (1998).

32. Panick, G., Vidugiris, G. J. A., Malessa, R., Rapp, G., Winter, R. \& Royer, C. A. Exploring the temperature-pressure phase diagram of Staphylococcal Nuclease. Biochemistry 38, 4157 4164 (1999).

33. Ravindra, R. \& Winter, R. On the temperature-pressure freeenergy landscape of protein. Chem. Phys. Chem. 4, 359-365 (2003).

34. Sasahara, K., Sakurai, M. \& Nitta, K. Pressure effect on denaturant-induced unfolding of hen egg white lysozyme. Proteins 15, 180-187 (2001). 